\title{
An accurate measurement of densities of snowflakes using 3-D microphotographs
}

\author{
MASAAKI ISHIZAKA \\ Toyama Science Museum, 1-8-31, Nishi-Nakano, Toyama 939, Japan
}

\begin{abstract}
A 3-D microphotographic method was developed to measure densities of snowflakes accurately. Microscopic observations and photographs were taken in the field. The volume of a snowflake which is an aggregate of snow crystals was estimated from the 3-D photo by polyhedron approximation. The weight of the snowflake was measured with an electro-balance. The density values obtained were compared with the degree of riming and the size of each snowflake. The results clearly show that riming is a prime factor in increasing the density of the snowflake. The density of a snowflake is not sensitive to the change of size of the flake itself, but depends slightly on the size of its constituent snow crystals. The technique developed here will be applied in the future to study of the density of falling snowflakes.
\end{abstract}

\section{INTRODUGTION}

During winter in the coastal region of the Sea of Japan, falling snow particles are generally snow crystal aggregates. Particularly in the Hokuriku District, graupel or densely rimed snowflakes fall when the air temperature is near the melting point.

Many studies have been made on rimed snowflakes. Harimaya and Sato (1992) examined the riming proportion in snowflakes falling on coastal areas. Fujiyoshi and Wakahama (1985) investigated the relationship between precipitation intensity and types and size distribution of snowflakes. In these studies each snowflake was separated into its constituent snow crystals for the detailed observations. Several authors have pointed out that the falling velocity of a snow particle depends on its density (Magono and Nakamura, 1965; Zikmunda, 1972). Magono and Nakamura (1965) calculated snowflake density under certain assumptions and determined a relationship between density and size.

This study presents a method to measure density of snowflakes with irregular shape. Snowflake density was obtained by estimating volume with $3-\mathrm{D}$ photos and by measuring mass directly with an electro-balance. The 3-D photo measurements of snowflakes are also useful to clarify their three-dimensional structure, as demonstrated by Iwai (1989).

\section{METHOD}

\section{Sampling and photography}

Snow particles were sampled in Toyama, Japan, during February 1992. The air temperature near the ground ranged from $-2^{\circ} \mathrm{C}$ to $+3^{\circ} \mathrm{C}$. Falling snow particles were captured on a plastic plate in a sampling case
$(0.11 \times 0.07 \times 0.035 \mathrm{~m})$ which had been kept at $-20^{\circ} \mathrm{C}$ until the sampling started. Stereo-photomicrographs of snowflakes were taken with a stereo-microscope (Nikon SMZ-10) using care not to change each snowflake's position. The schematic illustration of the apparatus is shown in Figure 1. For this stereo-microscope each optical axis inclines $6.9^{\circ}$ from vertical. Two electric flash lights were used to take photographs with an exposure time short enough to prevent the snow particle from melting $(1 / 60 \mathrm{~s})$. Then the snow particle was lifted with a fine needle to the dish of an electro-balance and the mass of the particle was directly measured to the order of submilligram.

The density values obtained in this study are of snowflakes captured on a flat plate and not of snowflakes falling through the air. The flakes may have been deformed when they fell onto the plate.

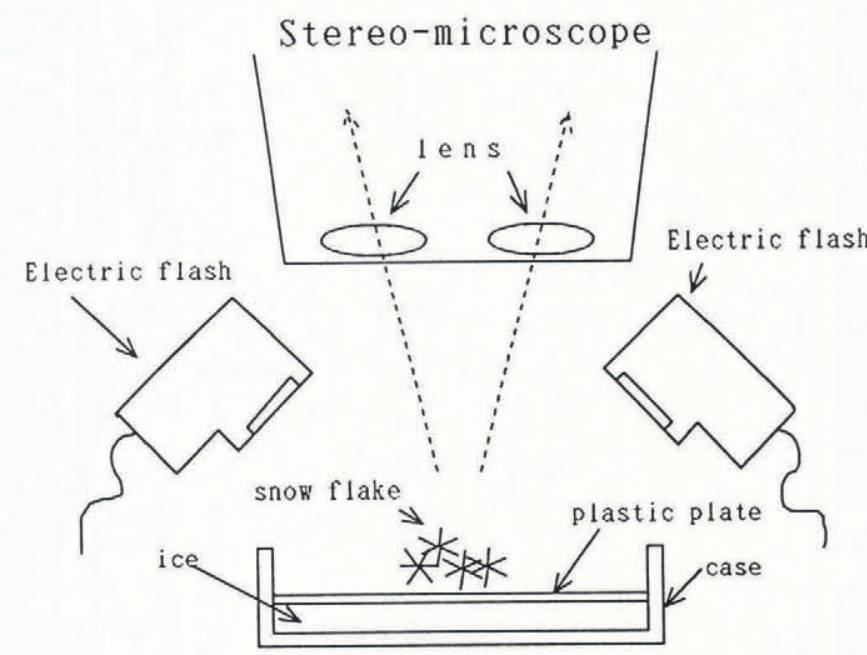

Fig. 1. Schematic of stereo-photomicrograph apparatus. 
Ishizaka: Accurate measurement of snowflake densities using 3-D microphotographs

a

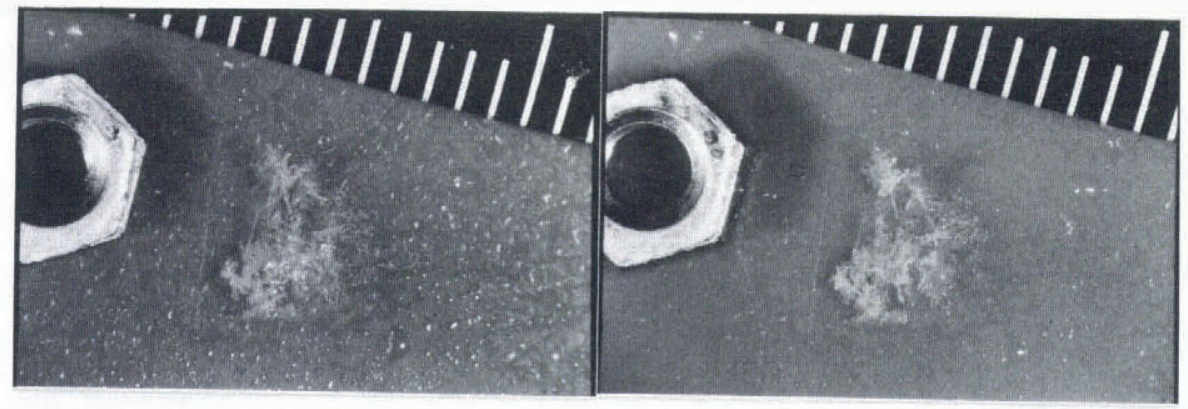

b

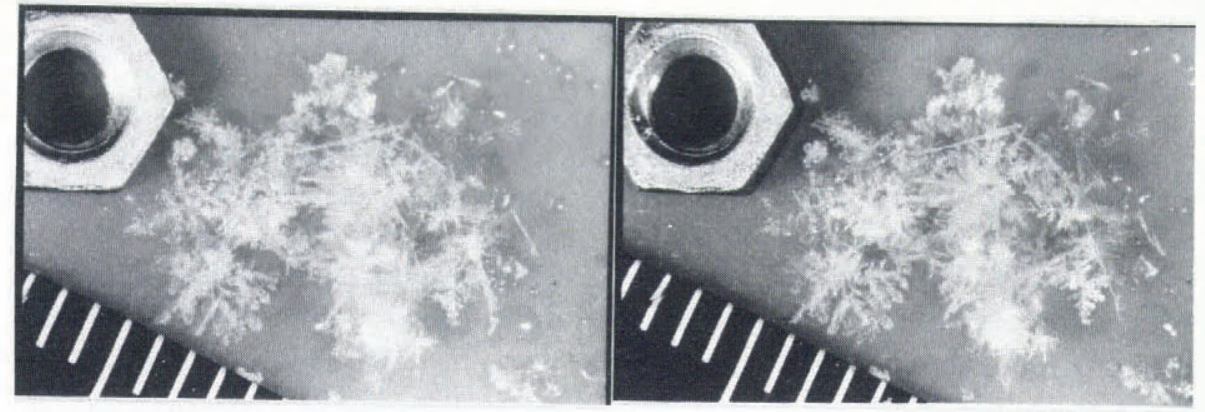

C

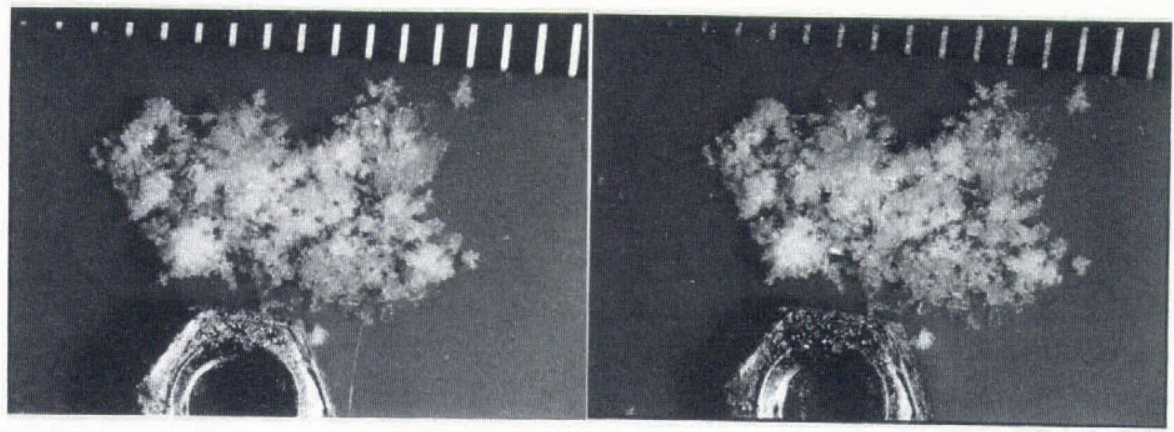

d

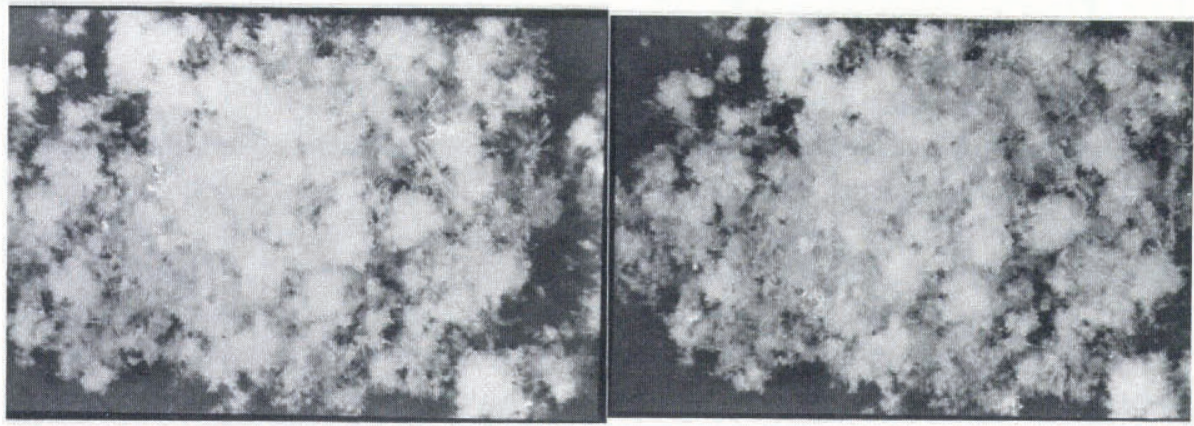

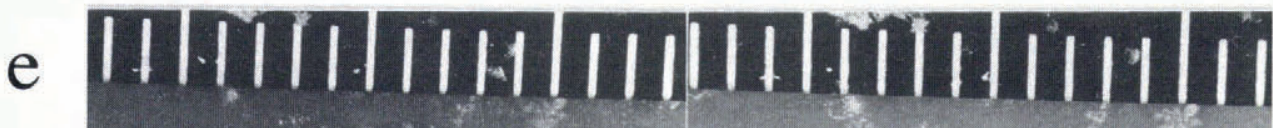

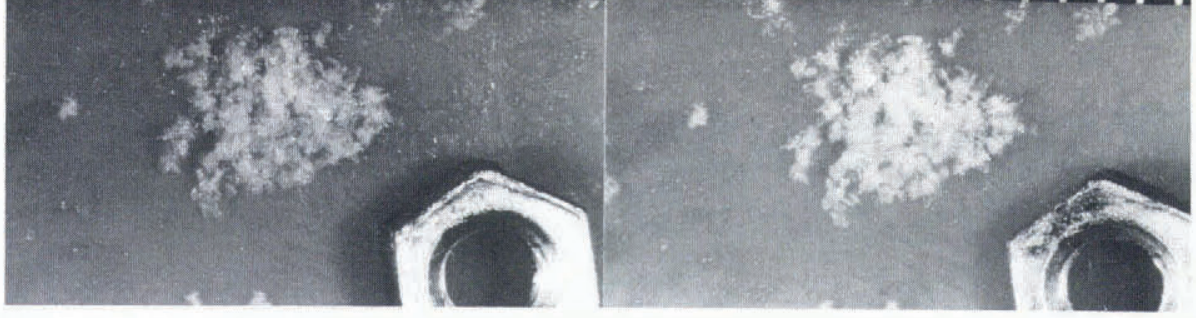

Fig. 2. 3-D photographs of snowflakes: $a$, unrimed or slightly rimed; $b$, moderately rimed; $c$, densely rimed; $d$, aggregate of graupel-like particles; e, melting snowflake. The nuts were used to calibrate focus.

\section{Classification of snowflakes}

54 snow particles were sampled, photographed and weighed. Almost all snowflakes observed consisted of dendritic snow crystals. These snowflakes were classified into five categories according to degree of riming (disregarding the type of individual snow crystals): a, unrimed or lightly rimed; b, moderately rimed; c, densely rimed; $d$, aggregate of graupel-like particles; and e, melting snowflake. Graupel were also classified into three types: a, lump, b, conical; and c, melting. Figures 2 and 3 show the 3-D photos of snowflakes and three types of graupel. The degree of riming of a snowflake was estimated from the amount of accreted frozen droplets 

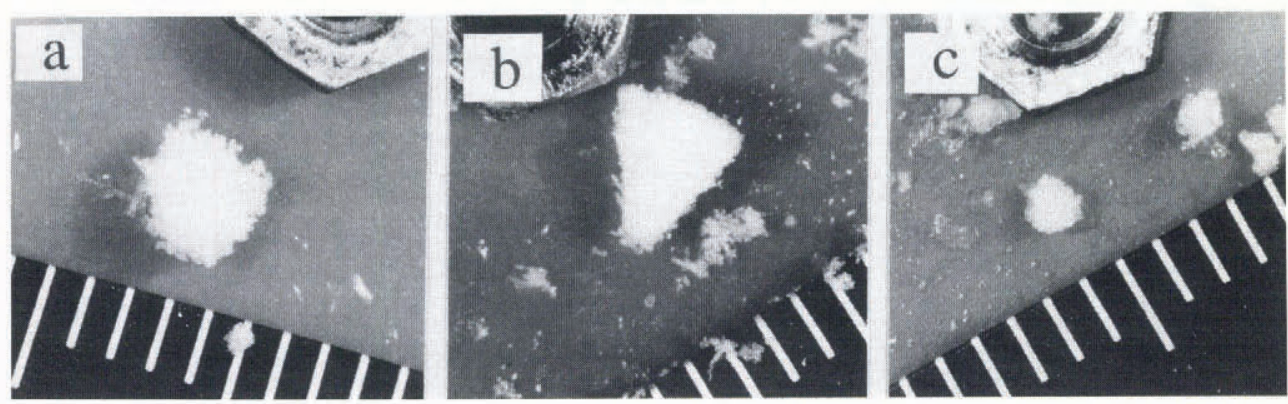

Fig. 3. Types of graupel observed: $a$, lump; $b$, conical; $c$, melting graupel.

seen by examining the 3-D photos with a stereoscope. If each snow crystal of a snowflake was discernible, the flake was classified as "moderately" rimed, and if not as "densely rimed". Snow flakes with small graupel or graupel-like particles were classified as "aggregate of graupel-like particles". Without the use of 3-D photos, it would be quite difficult to distinguish between "aggregate of graupel-like particles" and "densely rimed" snowflakes.

\section{Estimation of the volume of aggregates}

Figure 4 shows a pair of stereo-photomicrographs of an irregular-shaped snowflake. The grid on the right photograph has an interval of $1 \mathrm{~mm}$. The vertical dimensions of the snowflake at each cross-point were obtained as follows. First the corresponding points of the snowflake were identified on the two photographs. Then the relative distances (X component) of the point from the origin set at the base surface were measured on each photograph using a digitizer. Generally the two relative distances measured differed from each other and the difference was proportional to the vertical dimension of the point. To ensure proportionality, a few points were photographed and the difference of the relative distances compared with the known vertical dimensions (altitude). The result shown in Figure 5 reveals that the altitude of points is proportional to the difference of the relative distances. From this relationship between the difference of relative distances on 3-D photo and real altitude, the vertical dimensions of each cross-point are obtained.
Figure 6a shows the contour bands of the snowflake shape obtained by analyzing the 3-D photos shown in Figure 4, and Figure 6b shows a wire frame expression (polyhedron) of the same snowflake. The volume of the snowflake was approximated to that of this polyhedron.

When a finer grid is used, the polyhedrons can reflect more detailed roughness of the snowflakes, but an interval smaller than $1 \mathrm{~mm}$ leads to difficulty in finding the same position of the flake on 3-D photos. Only a few measurements could be made with $0.5 \mathrm{~mm}$ grid scale in this study.

The dimensions of graupel were measured directly on 3-D photos, but the volumes were estimated by using sphere or cone approximations.

\section{RESULTS AND DISGUSSIONS}

\section{The relationship between density and type of snow particles}

54 snow particles were photographed and the density values of 31 particles, including 7 graupel, were examined. The results are shown in Figure 7. The abscissa indicates the diameter of a sphere having the same volume as the approximated polyhedron (for type a, $\mathrm{b}, \mathrm{c}, \mathrm{d}$ and e) or sphere/cone (for graupel).

The densities of four lump-type graupel were distributed in a narrow range from $0.11 \mathrm{~g} \mathrm{~cm}^{-3}$ to $0.13 \mathrm{~g} \mathrm{~cm}^{-3}$. These values agree well with the observed value of $0.125 \mathrm{~g} \mathrm{~cm}^{-3}$ obtained by Nakaya (1954). The

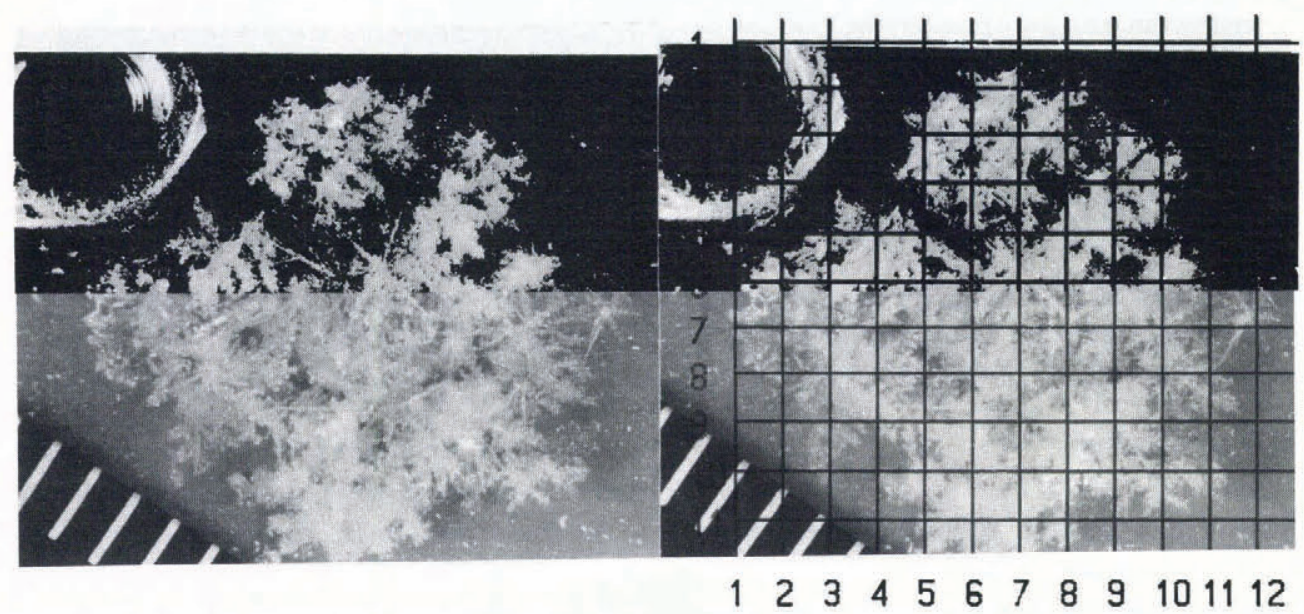

Fig. 4. 3-D photographs of a snowflake. The $1 \mathrm{~mm}$ grid is for measuring the vertical dimensions of the snowflake at each cross-point. 


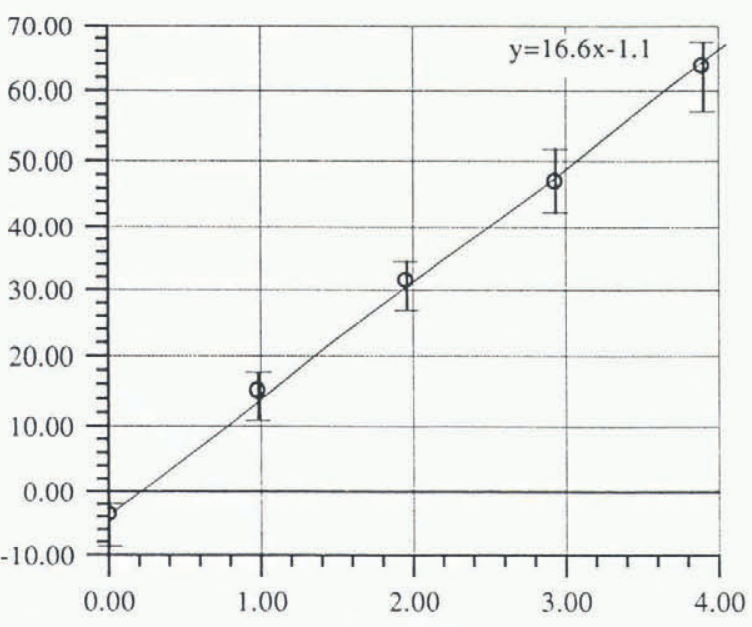

altitude $(\mathrm{mm})$

Fig. 5. The difference between the relative distances of the corresponding points is plotted against the real altitude (vertical dimension).

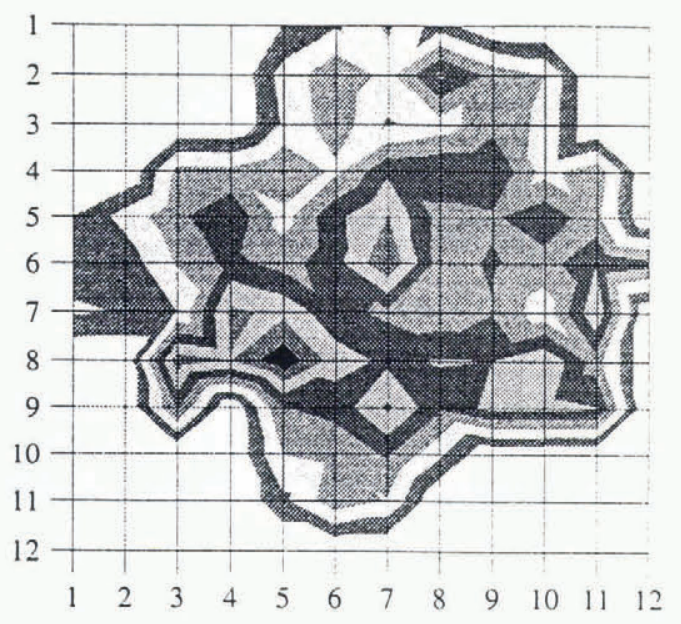

(mm)
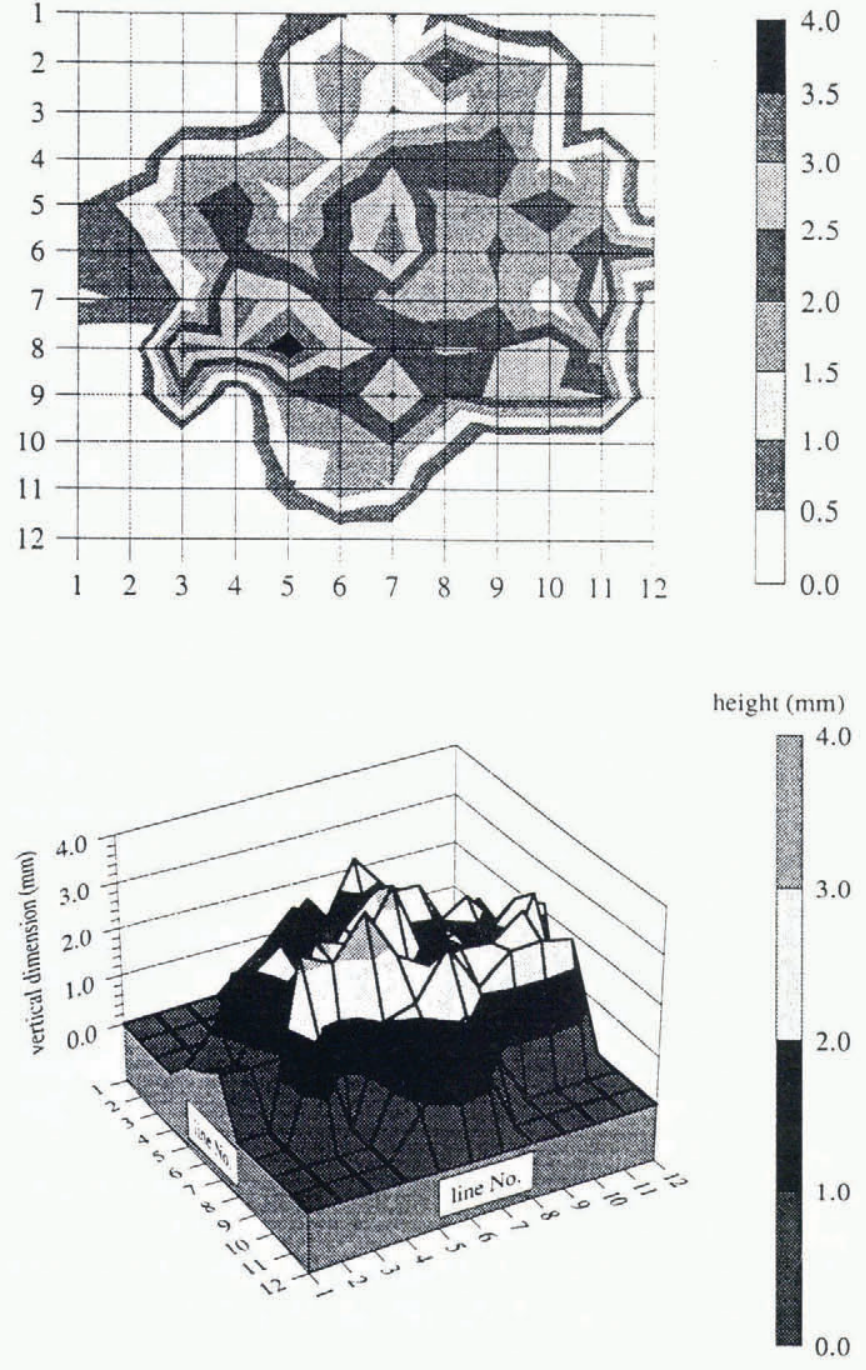

Fig. 6. a, surface contour bands of snowflake shown in Fig. 4 obtained by analyzing 3-D photos. $b$, wire-frame expression of the polyhedron of snowflake in $a$.

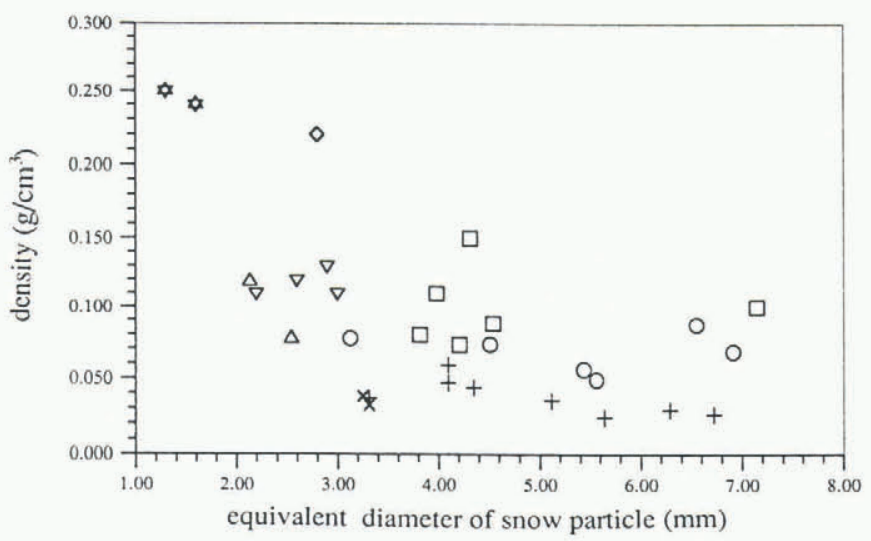

Fig. 7. Densities of snow particles. $\mathrm{X}$, unrimed or slightly rimed; + , moderately rimed; $\bigcirc$, densely rimed; $\square$, aggregate of graupel-like particles; $\triangle$, melting snowflake; $\nabla$, lump graupel; $\diamond$, conical graupel; $\$$, melting graupel.

density of a conical-type graupel was rather high and that of a melting graupel was the greatest of all snow particles examined in this study.

Figure 7 shows a clear dependency of density on type of snowflake. That is, a higher degree of riming increases the density of a snowflake in general. For moderately rimed snowflakes (type b), the density slightly decreases with increasing diameter. Detailed examinations of the 3D photos revealed that larger snowflakes generally consist of larger snow crystals and contain more space than smaller snowflakes. No clear link between density and diameter can be seen for the other types of snowflakes.

\section{Grid-scale dependence of the density}

The volumes of snowflakes (type a, b, c, d and e) were estimated from that of the polyhedron with a $1 \mathrm{~mm}$ interval grid. However the scale may affect the estimated volume: to examine the dependency of the densities on the grid scale, snowflake volumes were measured with 1, 2 and $4 \mathrm{~mm}$ interval scales. The volume of snowflakes was also estimated from projected-area equivalent diameter for comparison to other studies. The projected area of a snowflake is obtained by using two techniques, ellipsoidal approximation (Magono and Nakamura, 1965) and area approximation. The diameter is then given by $\sqrt{a \cdot b}$ (where $a$ and $b$ are two principal axis lengths of the ellipsoid approximation) or given by $\sqrt{A / \pi}$ (where $A$ is projected area). The densities of 24 snowflakes were measured and the result is shown in Figure 8. The density value is normalized to a $1 \mathrm{~mm}$ grid value. For the polyhedron approximation with 1,2 and $4 \mathrm{~mm}$ grid scales, density data are less scattered with the smaller scales. When snowflakes were measured with $0.5 \mathrm{~mm}$ grid scale, the density values stayed the same as those with $1 \mathrm{~mm}$ grid scale $( \pm 10 \%)$. Good repetition at the smaller grid scale suggests that polyhedrons with $1 \mathrm{~mm}$ grid scale are quite representative for irregular-shaped snowflakes. This grid scale of $1 \mathrm{~mm}$ is comparable to the size of constituent snow crystals $(1-3 \mathrm{~mm})$, which could allow the polyhedron to reflect the major irregularity of snowflake surface topography.

Figure 8 also shows that the sphere approximation 


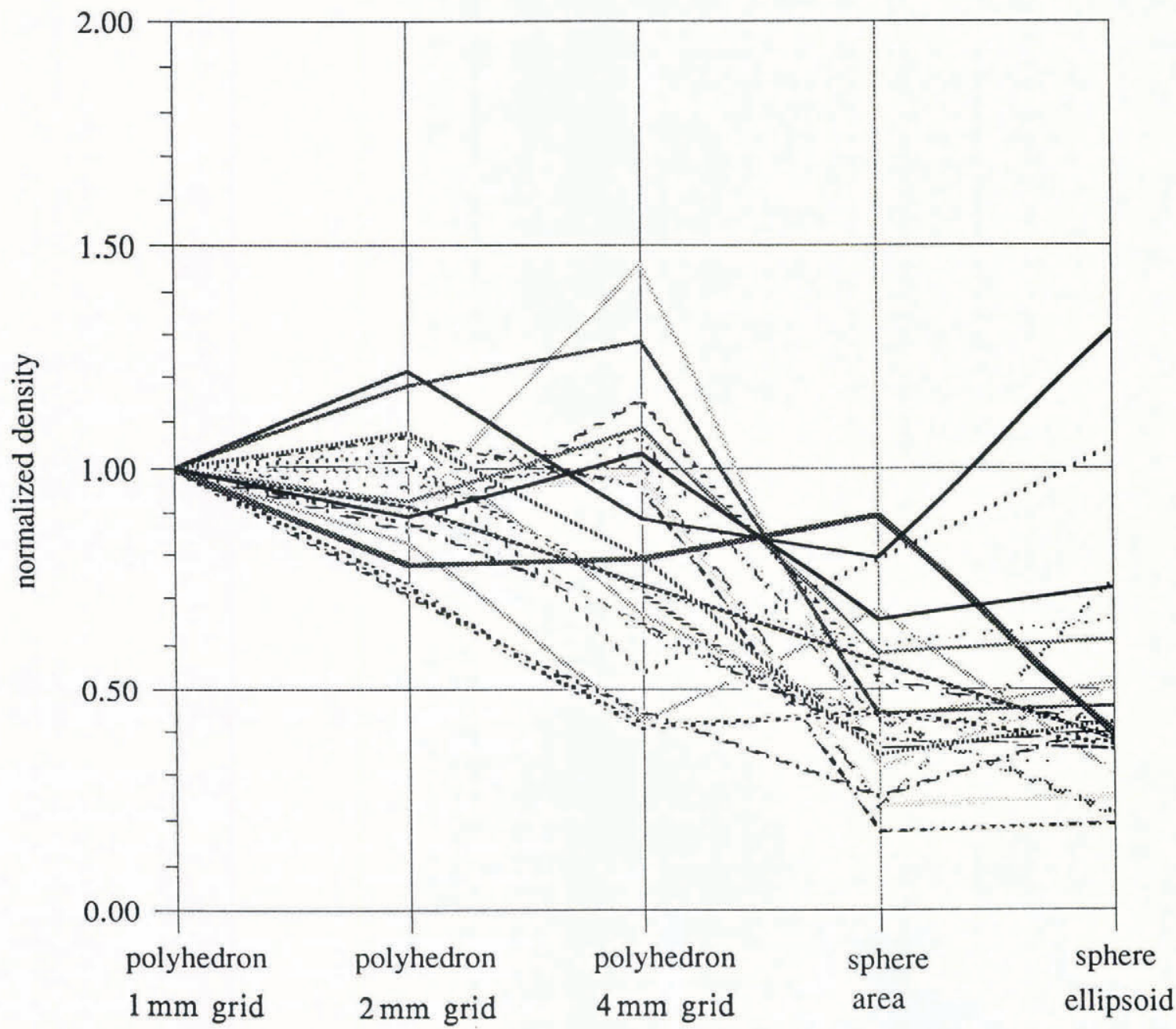

Fig. 8. Normalized densities obtained with five types of approximation. Normalized density is the density ratio at a $1 \mathrm{~mm}$ grid value. The densities of 24 snowflakes were examined.

with projected-area equivalent diameter tends to give lower density values than the polyhedron approximation. This tendency results from the overestimated volume obtained from the sphere approximation.

\section{SUMMARY}

An accurate measurement technique has been developed to investigate snow-flake density. Five types of snowflakes with different degrees of riming and three types of graupel were sampled and photographed in the field. The volume of each snowflake was measured by using a polyhedron approximation with 1,2 and $4 \mathrm{~mm}$ grid scales. The experimental results show that a polyhedron with $1 \mathrm{~mm}$ grid scale is quite representative for the shape of a snowflake. The weight of each flake was measured by electro-balance. The density of a snowflake depends mainly on its type (degree of riming), and to a minor extent on the size of its constituent snow crystals. No apparent dependency of density on snowflake size (equivalent diameter) has been observed in this study.

\section{ACKNOWLEDGEMENTS}

The author would like to express his thanks to Professor S.
Kobayashi, Niigata University, for his comments and Dr H. Shoji, Toyama University, for his helpful suggestions. $\mathrm{He}$ also thanks an anonymous reviewer for his valuable discussions.

\section{REFERENCES}

Fujiyoshi, Y. and G. Wakahama. 1985. On snow particles comprising an aggregate. F. Atmos. Sci., 42, 1667-1674.

Harimaya, T. and M. Sato. 1992. The riming proportion in snow particles falling on coastal areas. F. Meteorol. Soc. Jpn, 70(1), 57-65.

Iwai, K. 1989. Three-dimensional structures of natural snow crystals shown by stereo-photomicrographs. Atmos. Res., 24, 137-147.

Magono, C. and T. Nakamura. 1965. Aerodynamic studies of falling snowflakes. F. Meteorol. Soc. Jpn, 43(3), 139-147.

Nakaya, U. 1954. Snow crystals, natural and artificial. Cambridge, MA, Harvard University Press.

Zikmunda, J. 1972. Fall velocities of spatial crystals and aggregates. F. Atmos. Sci., 29(8), 1511-1515.

The accuracy of references in the text and in this list is the responsibility of the author, to whom queries should be addressed. 